\title{
Extractional - Spectrophotometric Determination of Fenbendazole and Ornidazole in Pharmaceutical Formulations
}

\author{
ALI Z. ABU ZUHRI ${ }^{\text {(1), }}$ WOLFGANG VOELTER ${ }^{\text {2) }}$, SULEIMAN AL-KHALIL ${ }^{1)}$, \\ AND IMAD SALAHAT ${ }^{1)}$ \\ 1) Chemistry Department, and Medical Tech. Department, An -Najah National University, \\ Nablus, Palestine. \\ 2) Abteilung für Physikalische Biochemie des Physiologisch Chemisches Instituts der \\ Universitut Tübingen, Hoppe- Selyer Straśe 4, D-72076 Tübingen, Germany \\ Keywords : Spectrophotometric determination, fenbendazole, ornidazole, \\ pharmaceutical formulations
}

\begin{abstract}
Methods for spectrophotometric determination of fenbendazole and ornidazde are described. The methods are based on the formation and extraction of the ion-pair complex formed between bromothymol blue and either fenbendazole (FBZ) or ornidazole (ORN). The extracted coloured complexes absorb at 416 and $446 \mathrm{~nm}$, respectively. The effect of different factors, e.g. $\mathrm{pH}$, organic solvent, reagent concentration, extraction time, shaking time and common interfering species have been investigated.

Fenbendazole and ornidazole can be determined over the range 1.2 to $24.0 \mathrm{ppm}$ and 5.5 to $77.0 \mathrm{ppm}$, respectively. The precision of the methods was tested for the determination of pure samples of FBZ and ORN and the mean RSD was found to be 3.0 and $2.3 \%$ for FBZ and ORN, respectively.
\end{abstract}


The proposed methods were successfully applied for the determination of FBZ and ORN in commercially dosage forms. A comparison between the suggested methods and the other reported methods was also studied.

\section{Introduction}

Fenbendazole (I) [methyl-5-(phenyl-thio) benzimidazole -2- carbamate] and ornidazole (II) [ -chloromethyl-2-methyl-5- nitroimidazole -1 - ethanol] are derivatives of benzimidazole and nitroimidazole, respectively.

These drugs have an antimicrobial action : they are used in the treatment of susceptible protozoal infections and in the treatment of bacterial infection.<smiles>CC(=O)Nc1nc2cc(Sc3ccccc3)ccc2[nH]1</smiles>

(I) fenbendazole<smiles>Cc1ncc([N+](=O)[O-])n1CCOCCl</smiles>

(II) ornidazole

Various methods have been reported for the determination of the investigated drugs in different biological samples, including high performance liquid chromatography [1-4], liquid chromatography [5-7], voltammetric methods (for ornidazole only) [8-10] and spectrophotometric methods [11-13].

To the best of our knowledge, there is only one published study concerning the spectrophotometric determination of fenbendazole in pharmaceutical formulations [11]. On the other hand, a little attention has been paid for the determination of ornidazole [12-13] using spectroscopic methods.

The aim of the present work was to develop a new sensitive, selective and accurate spectrophotometric method for the determination of fenbendazole and ornidazole in pharmaceutical formulations. The method is based on the extraction of the coloured 
ion-pair complexes formed between bromothymol blue and drugs, a new method for their determination of these two drugs.

\section{Experimental}

\section{Apparatus :}

A Pye-Unicam UV-visible spectrophotometer, model UV-2 was used for spectrophotometric measurements. The cells used for measurements were $1 \times 1 \mathrm{~cm}$ quartz cells. A Hanna 8521 model $\mathrm{pH}$ meter was used for $\mathrm{pH}$ measurements

\section{Reagents and materials}

Ornidazole and febendazole were supplied from Sigma and used as working standards. Bromothymol blue (BTB), and chloroform were manufactured by Aldrich. All chemicals were of analytical grade and manufactured by Merck and BDH. Water was doubly - distilled and stored in a glass container.

\section{Solutions}

A freshly prepared $1.0 \times 10^{-3} \mathrm{M}$ aqueous solution of pure ornidazole was used as stock solution. A $1.0 \times 10^{-3} \mathrm{M}$ fenbendazole was prepared by dissolving the appropriate amount of drug in chloroform. Bromothymol blue (BTB) solutions $\left(1.0 \times 10^{-3} \mathrm{M}\right)$ were prepared by dissolving the appropriate amounts in about $2 \mathrm{ml}$ of $0.1 \mathrm{M}$ sodium hydroxide, then $20 \mathrm{ml}$ of ethanol (96\%) were added and the volume was completed to exactly $100 \mathrm{ml}$ using double distilled water. Britton Robinson buffers were prepared according to the method listed in the literature . 


\section{Recommended procedure for determination of fenbendazole}

Into a $100-\mathrm{ml}$ separatory funnel, exactly $2.0 \mathrm{ml}$ of $1.0 \times 10^{-3} \mathrm{M}$ BTB were transferred, followed by $5.0 \mathrm{ml}$ of buffer of the recommended $\mathrm{pH}$ and mixed. Then, an appropriate volume of drug containing an amount of FBZ in the range 1.2-24.0 $\mu \mathrm{g} / \mathrm{ml}$ was added and the volume completed to $12 \mathrm{ml}$ with water. The aqueous solution was extracted with 20 - ml portions of chloroform, and shaked well to ensure complete extraction (for $1 \mathrm{~min}$ ). The extract was diluted to $25.0 \mathrm{ml}$ with chloroform and the absorbance was determined in a tightly stoppered cell at $416 \mathrm{~nm}$ at $25^{\circ} \mathrm{C}$ against a reagent blank prepared similarly without the addition of FBZ.

\section{Recommended procedure for determination of ORN}

Exactly $7.0 \mathrm{ml}$ of $1.0 \times 10^{-3} \mathrm{M} \mathrm{BTB}$ solution were transferred into a $50-\mathrm{ml}$ separatory funnel. A volume $(5.0 \mathrm{ml})$ of the desired buffer solution was added, followed by a portion of the drug solution containing $5.5-77.0 \mu \mathrm{g} / \mathrm{ml}$ and then $7.0 \mathrm{ml}$ of chloroform. The mixture was shaken for $1 \mathrm{~min}$, and then allowed to stand for $2 \mathrm{~min}$. The organic layer was collected into a $10-\mathrm{ml}$ volumetric flask and the volume was completed to the mark with chloroform. The absorbance was measured at $446 \mathrm{~nm}$ against a reagent blank .

\section{Determination of FBZ in veterinary formulations}

Ten tablets of Panacur drug $(250 \mathrm{mg})$ were weighed out and finely powdered. A weight equivalent to $250 \mathrm{mg}$ FBZ (one tablet) was dissolved in $500 \mathrm{ml}$ chloroform at $40^{\circ} \mathrm{C}$ with stirring for 15 minute. The supernatent solution was filtered through $1.0-\mathrm{L}$ volumetric flask and the volume completed with chloroform. A $1.0 \mathrm{ml}$ of the final solution was used for the determination of FBZ, using the recommended procedure . 


\section{Determination of ORN in pharmaceutical formulations}

Ten tablets of each amboral $(500 \mathrm{mg})$ and tiberal $(500 \mathrm{mg})$ were weighed out and finely powdered. A weight equivalent to $500 \mathrm{mg}$ ORN (one tablet) of the drug was transferred into a $500 \mathrm{ml}$ beaker and stirred with $300 \mathrm{ml}$ doubly distilled water for 20 $\min$ at $40{ }^{\circ} \mathrm{C}$. The supernatent solution was filtered through a $1.0 \mathrm{~L}$ volumetric flask and the volume completed with doubly distilled water. $1.0 \mathrm{ml}$ of this solution was used for the determination of ORN using the recommended procedure .

\section{Results and Discussion}

Fenbendazole and ornidazole react with the $\pi$-acceptor bromothymol blue (BTB) to form ion-pair or charge transfer complexes. The yellow ion-pair complexes formed were completely extracted with chloroform and exhibited absorption maxima at 416 and $446 \mathrm{~nm}$ for FBZ - BTB and ORN - BTB complexes, respectively as shown in Fig. 1. Neither fenbendazole or ornidazole nor BTB alone exhibits any significant absorbance at 416 and $446 \mathrm{~nm}$, under the same conditions. On the other hand, the absorbance of the repeated chloroform extract of the remaining of the reaction mixture was insignificant.

Investigations of several experimental conditions were carried out to establish the most favourable conditions to achieve the maximum colour development for the quantitative determination of fenbendazole and ornidazole. These experimental conditions include effects of $\mathrm{pH}$, solvent, shaking time, temperature, buffer constituents and dye concentration. 


\section{Effect of $\mathrm{pH}$}

The effect of $\mathrm{pH}$ of the aqueous phase on the absorption maxima of the ionpairs formed was studied in the $\mathrm{pH}$ range 2-9. For ornidazole determination, at $\mathrm{pH}>4$, the two layers take a long time $(-15 \mathrm{~min})$ for complete separation, where it takes less than $1 \mathrm{~min}$ at $\mathrm{pH}$ 2. As shown in Fig. 2, maximum color development had been constant within the $\mathrm{pH}$ range $2-5$ for the fenbendazole -BTB complex and the maximum absorbance was observed at $\mathrm{pH} 3$ for the ornidazole - BTB complex. Therefore, the recommended optimum $\mathrm{pH}$ for further studies was found to be $\mathrm{pH} 2$ and 3 for the fenbendazole and ornidazole determination, respectively.

The effect of several types of buffer solution, such as Britton-Robinson, acetate and citrate buffer having the same $\mathrm{pH}$ value have been also investigated, and maxmium absorbance was achieved in the presence of Britton-Robinson and acetate buffer.. On the other hand, long time was needed for complete separation of aqueous and organic layers in the presence of acetate buffer. Therefore, theBritton-Robinson buffer was chosen to be the most suitable one for the determination of the two ion-pairs.

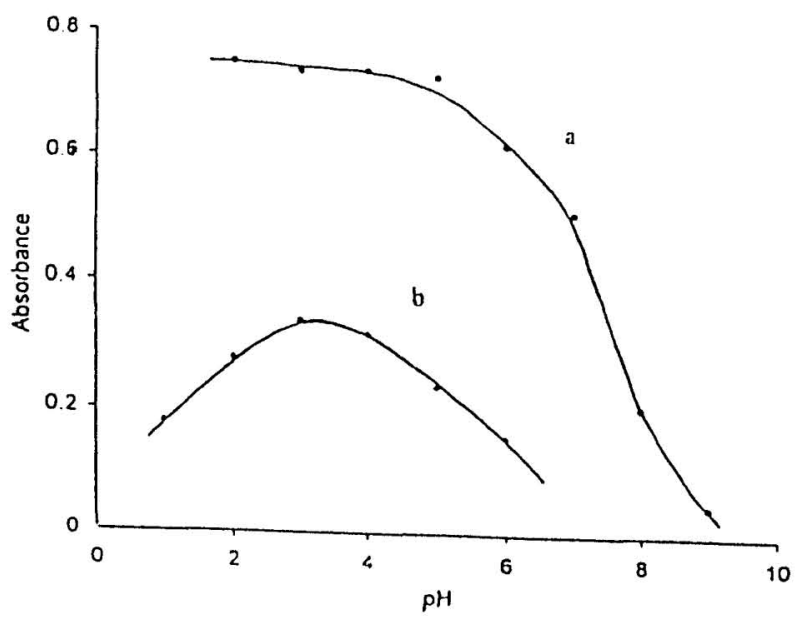

Fig. 2 Elfecl of pll on absorbance of a) FBZ-BTB and b) ORN-BTB ion pairs. 


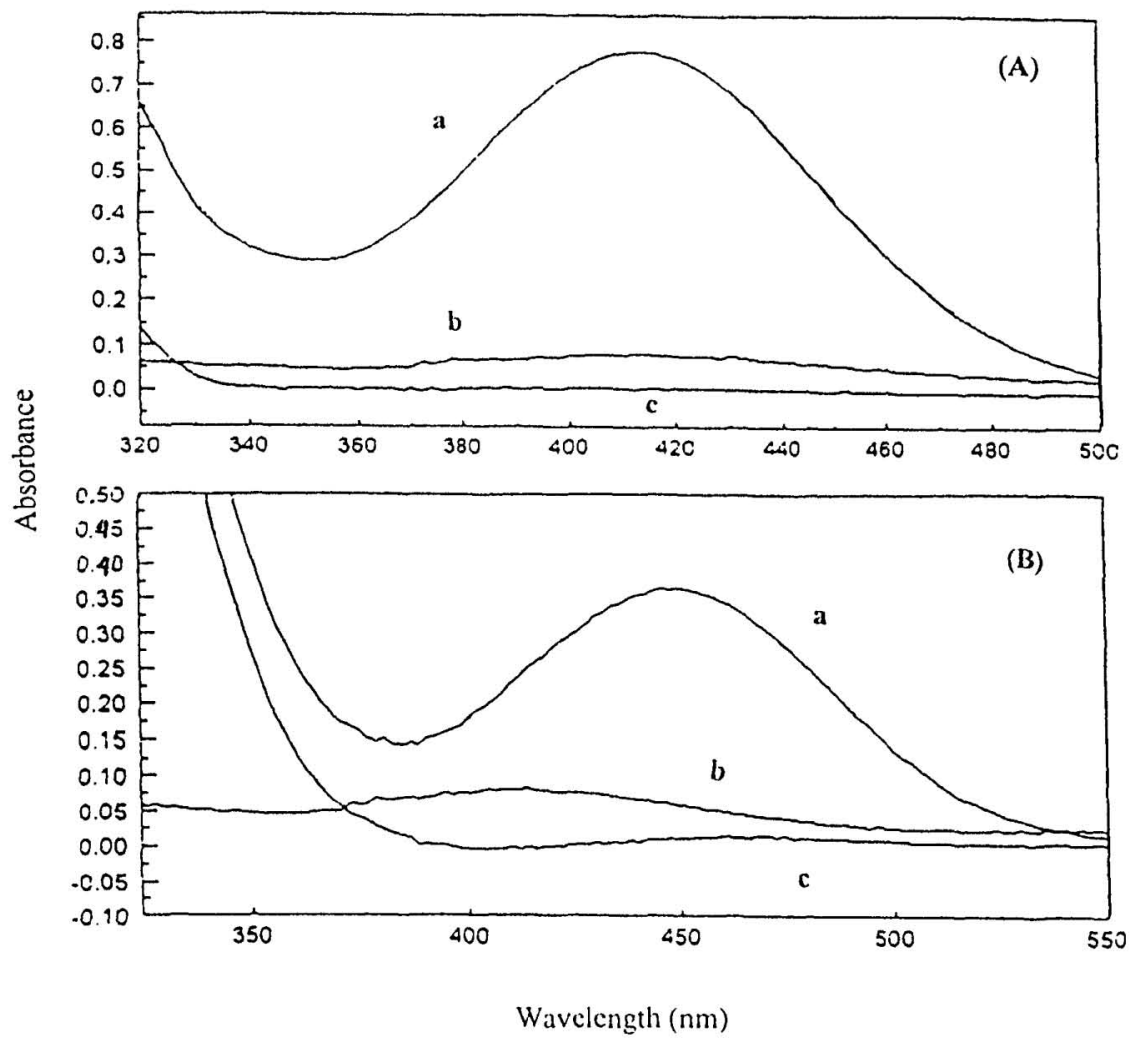

Fig. 1 (A) Absorption spectra of a) FBZ-BTB ion pair against a reagent blank, b) BTB against chloroform, c) FBZ against chloroform .

(B) Absorption spectra of a) ORN-BTB ion pair against a reagent blank, b) BTB against chloroform, c) ORN against chloroform. 
The effect of the buffer volume was studied by using a range of $1-7 \mathrm{ml}$, but no significant effect of the amount of buffer on the absorbance, could be observed.

\section{Effect of reagent concentration}

The effect of the concentration of BTB solutions on the absorbance was studied for solutions containing a fixed amount of $\mathrm{FBZ}$ and $\mathrm{ORN}$ and prepared as described in the general procedure. It was found that increasing the concentration of BTB affected a gradual increase in the absorbance up to a concentration of $6.0 \times 10^{-5} \mathrm{M}$ and $2.0 \times 10^{-4} \mathrm{M}$ in case of FBZ and $\mathrm{ORN}$, respectively. Any further increase in the dye concentration did not yield any significant increase in the absorbance, but it affected the formation of an emulsion causing a longer time for separation of the two phases .

\section{Effect of the solvent, number of extractions and time of extraction}

Various water - immiscible organic solvents, including carbon tetrachloride, diethylether, toluene, chloroform and dichloromethane were investigated. The complexes formed between BTB and each of ORN and FBZ were found to be completely extracted in chloroform. Therefore, chloforom was chosen to be the best solvent for further studies.

The amount of chloroform used for extraction of FBZ-BTB and ORN-BTB ionpair complexes was varied for study while keeping other variables fixed. Multiextraction was also tested for both ion-pair complexes. A single extraction with $10 \mathrm{ml}$ chloroform for 30-60 sec was sufficient for complete extraction of the ORN-BTB and FBZ-BTB ion-pairs. 


\section{Stability of the ion-pair complexes}

The stability of both ion-pair complexes was determined by measuring the absorbance at different time intervals. The color develops its maximum intensity within one minute after mixing $\mathrm{BTB}$ and each of $\mathrm{FBZ}$ or $\mathrm{ORN}$, and remains constant for at least 48 hours for both ion-pairs.

The effect of temperature on the absorbance of both FBZ-BTB and ORN-BTB ion-pair complexes was examined using the recommended procedure described earlier. It was found that the absorbances of ORN-BTB and FBZ-BTB ion-pair complexes were almost constant within the temperature range $15-35^{\circ} \mathrm{C}$. Above $35^{\circ} \mathrm{C}$, the absorbance decreases gradually

\section{Stoichiometry of the ion-pair complexes}

The stoichiometry of the ion-pair complexes formed between ORN or FBZ and BTB was investigated at the recommended $\mathrm{pH}$ by applying the molar ratio and continuous variation methods. The results indicated the existence of 1:1 ion-pair in all cases.

\section{Interference Effects}

Interferences by the common excipients, which are used in the preparation of pharmaceutical formulations of each FBZ and ORN were studied. The obtained results showed that glucose, sucrose, arabic gum, talc powder and magnesium stearate had no effect on the accuracy of the results when the additive to $\mathrm{FBZ}$ or ORN molar ratio did not exceed 100:1 


\section{Analytical applications}

Under the recommended conditions described, standard calibration curves for FBZ and ORN with BTB were constructed by plotting absorbance versus concentration. Beer's law was valid over the concentration ranges 1.2-24.0 and 5.5$77.0 \mathrm{ppm}$ for FBZ and ORN, respectively.

The precision of the methods of determination of both, FBZ and ORN, in pure raw materials was also checked. The determination of various concentrations of each drug was carried out using the recommended procedure. The mean relative standard deviations were found to be 3.0 and $2.3 \%$ for FBZ and ORN, respectively .

Table 1 summarizes the results obtained for the optimum conditions and spectral characteristics of the suggested methods for the determinations of FBZ and ORN in pure raw materials.

On the other hand, the validity of the proposed methods was assessed by applying the standard addition technique and the mean percent recovery of added standard ranges from $99.8-100.5 \%$ for FBN, and from $100.7-101.4 \%$ for ORN.

Table 1. The optimum conditions and analytical characteristics for the determination of FBZ and ORN

\begin{tabular}{lll}
\hline Parameter & FBZ method & ORN method \\
\hline$\lambda \max (\mathrm{nm})$ & 416 & 446 \\
Recommended pH & 2.0 & 3.0 \\
Shaking time (s) & 60 & 60 \\
Reagent (BTB) concentration (M) & $8.0 \times 10^{-5}$ & $2.8 \times 10^{-4}$ \\
Recommended temperature $\left({ }^{\circ} \mathrm{C}\right)$ & $25 \pm 0.2$ & $25 \pm 0.2$ \\
Linear range (ppm) & $1.2-24.0$ & $5.5-77.0$ \\
Correlation coefficient & 0.9998 & 0.9987 \\
Molar absorptivity $\left(\mathrm{Lmol}^{-1} \mathrm{~cm}^{-1}\right)$ & $1.9 \times 10^{4}$ & $1.9 \times 10^{3}$
\end{tabular}


$\begin{array}{lll}\text { Detection limit (ppm) } & 1.2 & 5.5 \\ \text { Mean r.s.d (\%) pure material } & 3.0 & 2.3\end{array}$

\section{Comparison of the proposed method with other methods}

Very few spectrophotometric and chromatographic methods have been reported for the determination of FBZ and ORN in pharmaceutical formulations. Table 2 shows a comparison between the proposed methods and other reported methods for FBZ and ORN determinations. It was found that the suggested method competes well with other methods in sensitivity and precision and it is suitable for routine analysis of FBZ and ORN in the dosage forms.

Table 2. Comparison between the results of analysis of FBZ and ORN in pharmaceutical formulations using the proposed and other reported methods

\begin{tabular}{llcccc}
\hline Drug & Method & Medium & $\begin{array}{c}\text { Linear range } \\
(\mu \mathrm{g} / \mathrm{ml})\end{array}$ & $\begin{array}{c}\text { Recovery } \\
(\%)\end{array}$ & Ref. \\
\hline FBZ & HPLC & $\mathrm{pH} \mathrm{3.6}$ & $8-41$ & 98.2 & 1 \\
& HPLC & $\mathrm{pH} \mathrm{4.2}$ & $100-400$ & 100.1 & 14 \\
& U.V-VIS Spectroscopy & Aceticacid & $5-15$ & 98.0 & 11 \\
& VIS-spectroscopy & $\mathrm{pH} \mathrm{3.0}$ & $1.2-24.0$ & 98.5 & This work \\
ORN & HPLC & $\mathrm{pH} \mathrm{5.5}$ & $20-200$ & 86.4 & 3 \\
& UV-Spectroscopy & Ethanol & $2-22$ & 101.7 & 13 \\
& Polarography & $\mathrm{pH} \mathrm{8-9}$ & $0.2-22$ & - & 8 \\
& VIS-Spectroscopy & $\mathrm{pH} \mathrm{3.0}$ & $5.5-77.0$ & 100.5 & This work \\
\hline
\end{tabular}

\section{Analysis of pharmaceutical formulations}

The applicability of the suggested methods for the determination of ORN and FBZ in commercial dosage forms was examined. Amboral tablets, each containing 500 $\mathrm{mg}$ of ORN (Eastren Chemical Company, Palestine), Tiberal tablets, each containing $500 \mathrm{mg}$ of ORN (Hoffman La Roche, Switzerland) and panacur tablets, containing 250 mg of FBZ per tablet (Hoechst AG, Germany) were analysed. The Results of the analyses of the above dosage forms using the suggested method compared to reference method are measured in Table 3. 


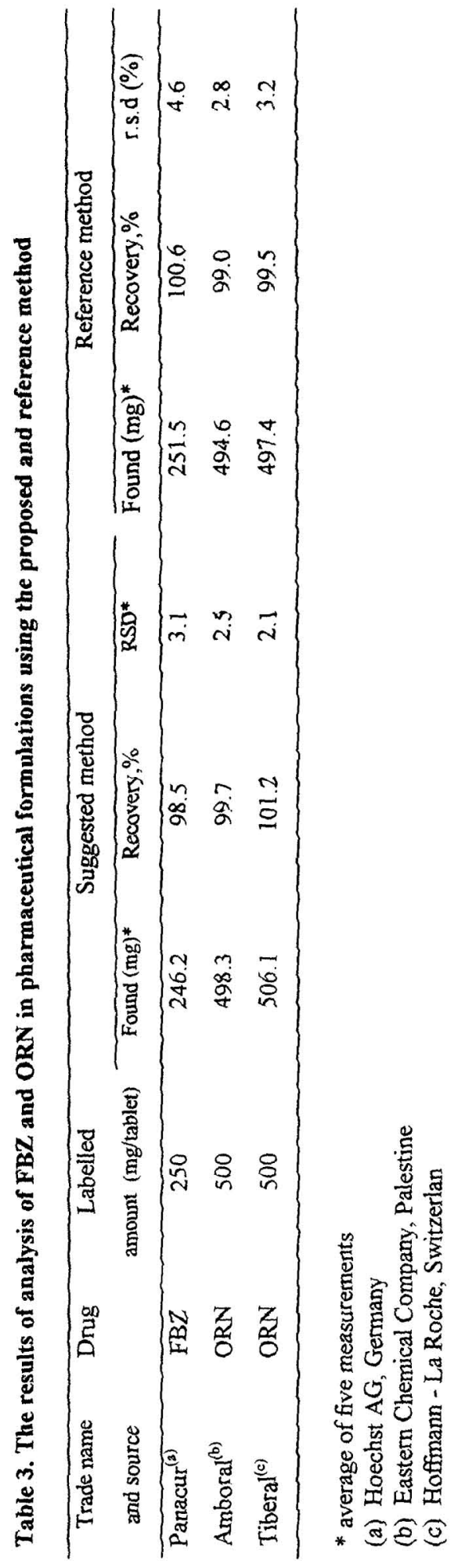




\section{Conclusion}

The proposed method is sensitive and easily applied, so it can be conveniently used for the routine quality control analysis of ORN and FBZ in pharmaceutical and veterinary formulations .

\section{Acknowledgments :}

The authors thank Deutscher Akademischer Austauschdients (DAAD), Bonn for financial support of a quest professorship awarded to Ali Z. Abu Zuhri.

\section{References}

1. van-Touder E.C.,de-Villiers M.N., Handford J.S., Malan C., du-Preez J.L.(1996), J. Chromatogr. 729:267

2. Botsoglou N.A., Fletouris D.J., Psomas I.E., Vassilopoulos V.N.(1994), J.Liq. Chromatogr. 17:4229

3. Ku Y.R., Tsai M.J., Wen K.C. (1996), Yaowu. Shipin. Fenxi. 4:141

4. Heizma P., Geschke R., Zinapold K., (1990), J. Chromatogr. Biomed. Appl. 99:233

5. Fletouris D.J., Botsoglou N.A., Psomas I.E., Mantis A.I. (1994) Analyst 119:2801

6. Fletouris D.J., Botsoglou N.A., Psomas I.E., Mantis A.I. (1996), J.AOAC.Int. 79:1281

7. Visna V., Ionescu M.S., Dragos M., Belu D., Cosofret V. (1989), Rev. Chim. (Bucharest)

8. Lopez I.M., Gomez-Rivera M.C.,Garacia-Monteagudo J.C. (1993) Anal. Lett. 26:109

9. Sankar P.S., Reddy D.J. (1990), Asian J. Chem. 2:245

10. Warowna M., Fijalek Z., Dziekauska A., Korzeniewska A. (1991), Acta Pol. Pharm. 48:17 
11. Thankar A. (1991), Indian Drugs 28:529

12. Msrciniec B., Bugaj A. (1994), Chem. Anal. (Warsaw) 39:705

13. Hassan M.M., Jado A.I., El-Shazly B.E. (1989), Spectrosc. Lett. 22:111

14. Sane R. T., Joshi M. D., Paurandore S. M., Tem P. B., Manikar P. S., Nayak V. (1989), Indian Drugs 26: 626. 